\title{
Student motivation for a degree on civil engineering
}

\author{
An ISEP first-cycle degree on civil engineering initiative
}

\author{
Diogo Ribeiro \\ School of Engineering \\ Polytechnic of Porto \\ Portugal \\ drr@isep.ipp.pt
}

\author{
Teresa Neto \\ School of Engineering \\ Polytechnic of Porto \\ Portugal \\ tis@isep.ipp.pt
}

\author{
Maria da Fátima Portela \\ School of Engineering \\ Polytechnic of Porto \\ Portugal \\ mfp@isep.ipp.pt
}

\author{
Ricardo Santos \\ School of Engineering \\ Polytechnic of Porto \\ Portugal \\ rps@isep.ipp.pt
}

\begin{abstract}
This paper describes an initiative of the first-cycle degree on civil engineering from the School of Engineering-Polytechnic of Porto (LEC-ISEP) promoting the early integration and motivation for the study of civil engineering. On the academic year of 2018/19 the direction board of the first cycle degree decided to implement the initiative EngenheiroCivil@Work (CivilEngineer@Work) destined exclusively to students of the first curricular year, with the purpose of giving these students a short and first presential contact with the practice of civil engineering and professional civil engineers on their own work environment.

The direction board of the degree has been monitoring this ongoing experience through enquiries and a close and continuous contact with all participants. For an experimental and novel initiative, the acceptance and involvement of the students, teachers and companies was very positive, although some aspects deserve further consideration and attention. This initiative was thought and is expected to contribute for the sustainability of the degree, namely the number of enrolled students, thru a motivation boost and an awakening on the general interest of civil engineering.
\end{abstract}

Permission to make digital or hard copies of all or part of this work for personal or classroom use is granted without fee provided that copies are not made or distributed for profit or commercial advantage and that copies bear this notice and the full citation on the first page. Copyrights for components of this work owned by others than ACM must be honored. Abstracting with credit is permitted. To copy otherwise, or republish, to post on servers or to redistribute to lists, requires prior specific permission and/or a fee. Request permissions from Permissions@acm.org.

TEEM'19, October 16-18, 2019, León, Spain

(C) 2019 Association for Computing Machinery.

ACM ISBN 978-1-4503-7191-9/19/10..\$15.00

https://doi.org/10.1145/3362789.3362911

\section{CCS CONCEPTS}

- Applied computing $\rightarrow$ Education; • Applied computing $\rightarrow$ Physical sciences and engineering $\rightarrow$ Engineering

\section{KEYWORDS}

Civil Engineering; EngenheiroCivil@work, Student motivation; short-term professional experience.

\section{ACM Reference format:}

Diogo Ribeiro, Teresa Neto, Ricardo Santos and Maria da Fátima Portela. 2019. Student motivation for a degree on civil engineering. An ISEP firstcycle degree on civil engineering initiative. In Proceedings of the Seventh International Conference on Technological Ecosystems for Enhancing Multiculturality (TEEM 2019) (León, Spain, October 16-18, 2019), ACM, New York, NY, USA, 6 pages. https://doi.org/10.1145/3362789.3362911

\section{Introduction}

The Architecture, Engineering and Construction (AEC) industry in Europe has suffered an important sector crisis in the last decade, with 2012/13 being its most severe period. In Portugal this sector crisis, appeared along with a conjunctural economic crisis giving it a further relevance, with negative growth rates of about $-16 \%$ in 2012 and $-14 \%$ in 2013 , on a country where the AEC industry represents about $6.3 \%$ of the total Portuguese workforce [1][2].

On the last few years, however, this tendency has been reverted, with the growth rate of the AEC sector in Portugal, surpassing the average values of the European space, as may be seen on Figure 1. 


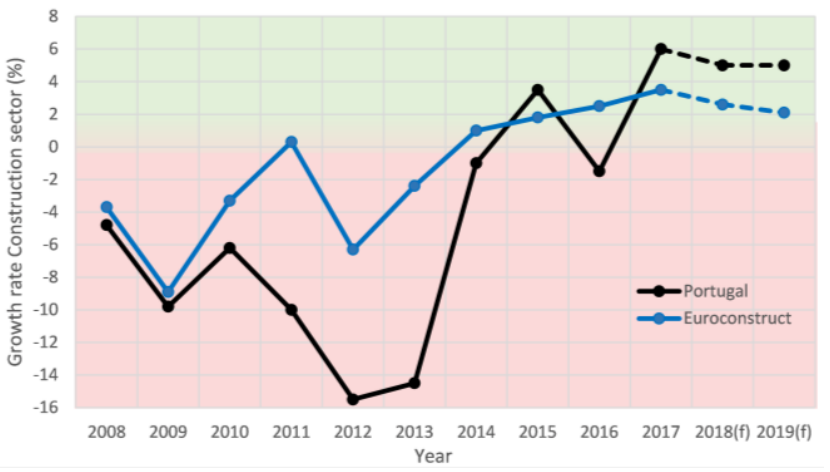

Figure 1: Growth rate evolution of the AEC sector in Portugal and Europe [1]

Along with this crisis on the AEC sector, there was a serious reduction in Portugal, on the procurement of higher education on Civil Engineering (Figure 2), mainly between the academic years 2011 and 2015, a fact that seems to imply that a strong correlation exists between employability and the students choice of a career, at least on the Science \& Technology areas. Some universities and polytechnic schools were faced, during this period, with serious problems of sustainability and some private schools were forced to suspend their offer on this area of knowledge. The number of students seeking a placement on LEC-ISEP at the National Competition for Access to Higher Education (CNA - Concurso Nacional de Acesso) [3] followed the general panorama verified at the national level, hitting a lowest level ever on the academic year 2014/15 with only one student.

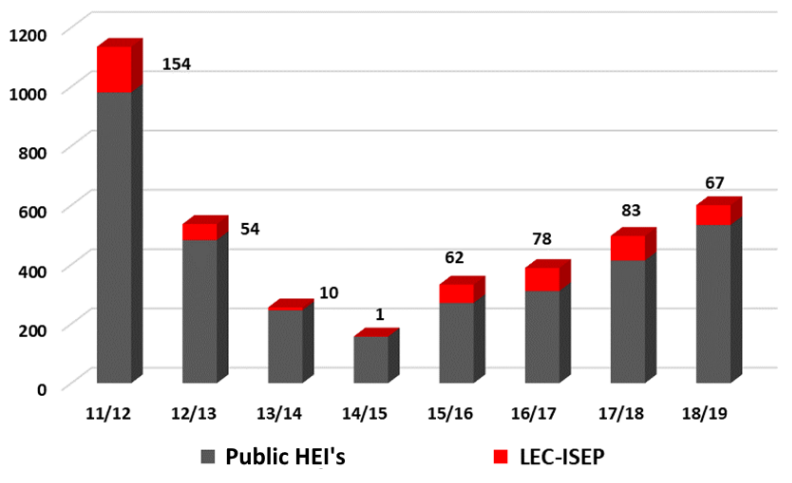

Figure 2: Evolution of the number of new students in civil engineering (according to the CNA)

Lately, starting on the academic year 2015/16, the AEC sector recovery gave the extra motivation needed for the gradual increase on the number of students, setting a turning point which resulted on the fulfillment of the available vacancies for the LECISEP, according to the CNA in the immediately following year, 2016/17. It is however important to note that the total number of vacancies available on the last academic years is about $50 \%$ of the number set for academic year 2010/2011. The analysis of this tendency may be easily visualized with the results of the CNA presented on Figure 3.

It is interesting to analyse the number of candidates that choose LEC-ISEP as their first choice on their application form to the CNA. On $2011 / 12$ more than $60 \%$ of the candidates (80 out of 130) set LEC-ISEP as their first choice but, since $2012 / 13$, that percentage fell abruptly to values in the vicinity of $10 \%$. On the current academic year, a significant increase was noted with $28 \%$ of the students (17 out of 60) setting LEC-ISEP as their first choice.

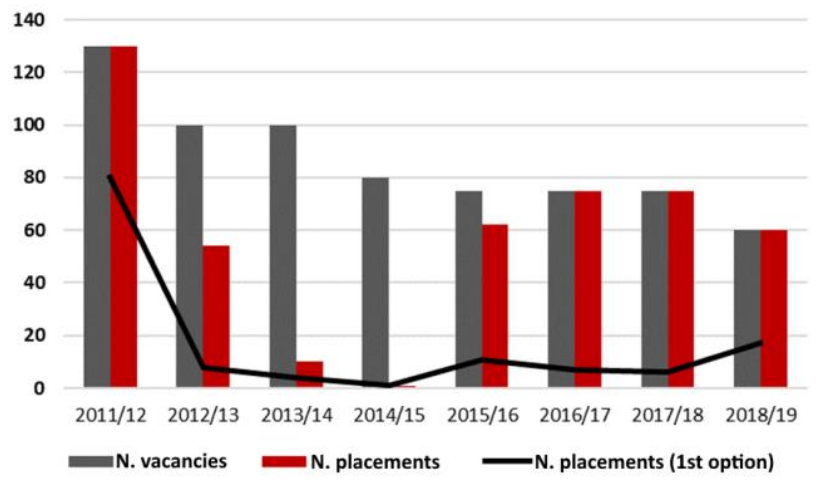

Figure 3: Evolution of the number of new students on LEC-ISEP (according to CNA)

Associated to the crisis in the AEC sector and its negative impact on the choice of civil engineering degrees, the general economic crisis forced several students to give up their prosecution of high studies or suspend their registrations. With a significant percentage of the students not having chosen civil engineering as their first option, it becomes all too common to have a significant number either of dropouts or requests for transfer to other degree courses at the end of the first curricular year. According to data collected with the academic services of ISEP, about 30 students cancel their registration each year.

Faced with this situation, ISEP and the direction board of the firstcycle degree on civil engineering, have been developing a series of initiatives to ease the integration and foster the motivation of civil engineering students, on a joint effort to try to attract and keep them on the course they chose, namely the degree on civil engineering.

ISEP promotes, at the beginning of each academic year, the INTEGRA seminar, with the following main purposes:

i. The familiarization of new students with the ISEP campus and ISEP resources;

ii. A reflection on the challenges and opportunities of Higher Education;

iii. The promotion of the identification of competences oriented for academic success, as well as the development of facilitating attitudes towards the general well-being and commitment to the career management. 
The implementation of this seminar on the first-cycle degree on civil engineering started with a presentation from the degree direction board with personal welcome of the direction board of the degree and relevant information on some particular aspects. According to the responsible for the ISEP|GO (ISEP - Guidance Office): "scientific investigation on the area and both national and international studies, the investment on welcome practices to new students, is shown to be positively correlated with the academic achievement; to ease the process of transition to Higher Education and academic integration, minimizes the effect of variables affecting academic performance and the students well-being, preventing situations of study drop-out or serious academic failure"[4].

On their arrival, students receive the "Manual de Acolhimento ao Novo Estudante" [5] ("Welcome Manual to New Students") with several pertinent information about the school and the campus, in order to ease their integration.

In order to develop the participation of students on extra-curricular initiatives, strengthen their feeling of "being part of the Institution", contribute to the creation of mechanisms that promote student's integration as well as being able to promote the development of transversal competences and soft-skills, a team of ISEP Ambassadors was created. This team, currently with 22 members, is formed by students that apply to the position annually and develop several support activities along the academic year, helping, representing and dignifying the school.

The direction board of LEC-ISEP has also contributed with some initiatives that promote the integration of first-year students, with a perspective of fostering their interest on the degree, by helping the development of personal relationships with sport events (see Figure 4), welcome sessions, interviews with students manifesting interest on transferring to other courses or, for instance, proposing in a partnership with the Department of Mathematics, the activity "Matemática, por onde andas?" (Mathematics, where are you?). This last activity main purpose is to show future engineers the importance of Mathematics as a fundamental tool on Civil Engineering. It is an innovating and extracurricular project for first year students beginning with the crossing between mathematical knowledge and engineering and ending on laboratory applications.

The direction board of the degree develops the planification of all scholar activities on the beginning and during each semester, scheduling intermediate evaluations, including assignments and final examinations, with the participation of student representatives, seeking to help all students, and most particularly first year students, in their transition between junior high and the polytechnic higher education. Regular meetings are held with the students in order to assess their degree of satisfaction and eventual identification and resolution of problems that may rise along the academic year.

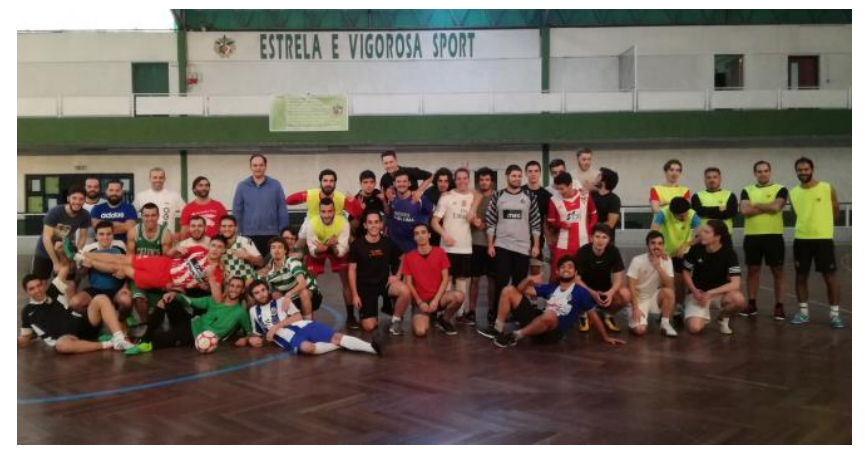

Figure 4: Football game: teachers vs students

On the academic year of 2018/19, the direction of LEC-ISEP decided to promote a novel and experimental initiative named EngenheiroCivil@Work (CivilEngineer@Work), destined exclusively to students of the first curricular year. This initiative proposes a very short-term and first presential contact with the practice of civil engineering and acting civil engineers on their own work environment. This initiative was thought as a way of promoting the early interest of students on practical aspects of the profession and consequently help to reduce mainly the number of students applying for course transfer, though consolidating the number of students and the course sustainability $[6,7]$.

\section{EngenheiroCivil@Work (CivilEngineer@Work)}

\subsection{Objectives}

The implementation of this initiative, exclusive to LEC-ISEP firstyear students, has the main principal objectives:

i. The develop the integration of first-year students;

ii. To allow the students a first, short-term experience with the profession of civil engineering, during an afternoon, on an actual civil engineering company location;

iii. The allow a broad perspective on the different options available on the civil engineering market;

iv. Allow the in-place contact of the students with civil engineers on their own work environment;

v. To have the chance of observe and follow the professional activity of a company/institution developing activities on construction, inspection, design or test and experimentation;

vi. Motivate the students for the study and practice of Civil Engineering.

An additional purpose of this initiative has to do with the normally somewhat limited and sometimes distorted vision from the part of the students of the civil engineering profession its possible areas of intervention and possible sub-specializations and the possibility to give the students an idea of their future role as 
civil engineers, existing companies in the market, emblematic constructions and important people in the area of specialization of their choice.

\subsection{Implementation}

On November 2018, the LEC-ISEP direction board promoted a meeting with the first-year students, in order to exhibit and explain the scope and implementation method of this initiative, namely:

i. Students are invited to spend an afternoon at a company in the AEC sector, accompanied by a civil engineer of that company, in order to directly observe and evaluate different activities related to the profession of a civil engineer;

ii. Activities will occur during both semesters and are extracurricular;

iii. Activities will be held preferably on Wednesday and Friday afternoons, in order to ensure that there are no conflicts with regular classes of first year students. In order to further minimize conflicts with other known activities of first year students, the activity schedule was made compatible with the set evaluation periods, study visits and regular talks promoted by the Civil Engineering Department;

iv. Each visit will be held on groups of 2 to 4 students;

v. Each student may and should apply to at least two activities depending on availability;

vi. All information on the participating companies and event dates was published on the Moodle page of the LEC-ISEP degree.

All companies participating on this initiative develop their activities on the construction, inspection, design or test and experimentation, some of them with experience and participation on $R \& D$ projects. Some visits were held to emblematic constructions on the regional area of ISEP, such as the construction of the new hospital of Trofa Saúde, a private company on the Health field.

On an initial phase, about 20 activities were proposed. For several reasons, only 14 of these collaborations took place (see Figure 5). Most of the reasons had to be with little or non-existent procurement of the activity from the students, because no compatible dates were found between the companies and students' availabilities or, in two occasions, because of a failure of the students to appear.

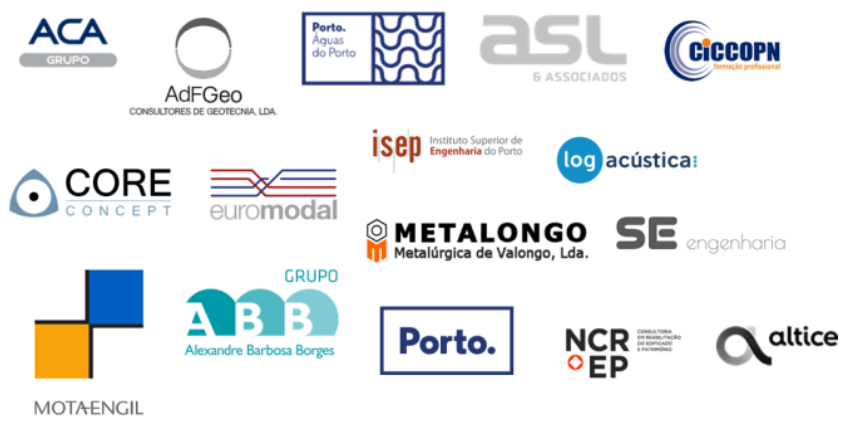

Figure 5: Partner enterprises

The students, after the first explanation session, chose their preferred activities using a Google Form. The groups and companies attributed to each group were chosen by the LEC-ISEP direction and were published on December $10^{\text {th }}$.

First activities took place still in December 2018 and included a visit to the Altice's telecommunications tower in Gaia (see Figure 6), and a construction site with a rehabilitation of an old building under the inspection of ASL \& Associados.
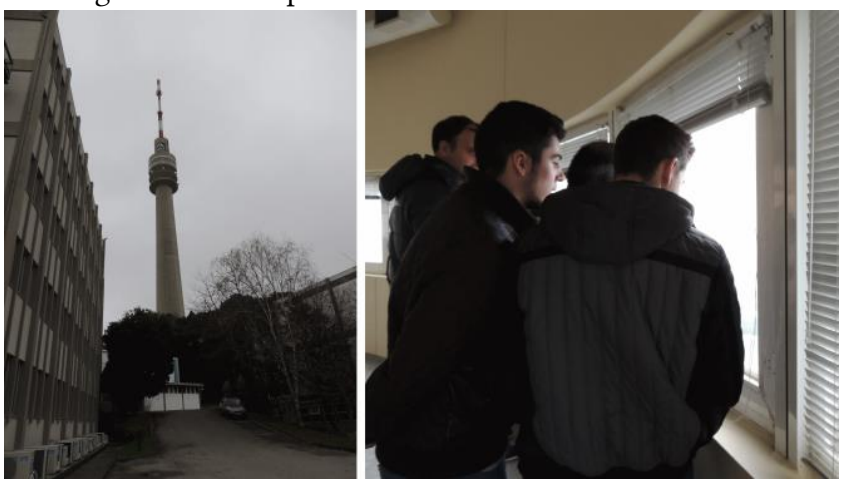

Figure 6: Visit to Altice's telecommunications tower

\subsection{Monitoring}

In order to evaluate this initiative, LEC direction board is analyzing:

i. The number of students enrolled on this initiative;

ii. The number of students that effectively participated on the activities;

iii. The results of a short student inquiry conducted by email;

iv. The personal reactions of the fellow engineers at the companies that welcome the students on this initiative.

A total of 30 different students enrolled for a total of 58 presences on activities. The first year of the degree has a total of 75 students giving a participation rate of $40 \%$. 
Up to the moment of writing, June 2019, 13 activities took place, with one remaining activity with Mota-Engil scheduled for the beginning of July, on company proposal.

Of the original 58 student participations, 27 were effective, being foreseeable 4 more participations, giving a participation rate superior to $50 \%$ (31 actual participations on 58 initially foreseen) (see Figure 7). This data shows a significant abstention from the part of the students with two activities failing to take place altogether due to the absence of the students, as mentioned before.

\begin{tabular}{|c|c|c|}
\hline Activities & Companies & Students \\
\hline Held & 13 & 27 \\
\hline To be held & 1 & 4 \\
\hline Total & 14 & 31 \\
\hline
\end{tabular}

Figure 7: Number of participating companies and students

At the end of each activity, an email was sent to the participating students, with a small enquiry developed in MSExcel. Figure 8 shows a sample of the enquiry sent with a total of 5 questions, for the evaluation of the level of satisfaction (results between 1-"not a all satisfied" and 5-"totally satisfied"). An open final question allows the students some suggestions or further aspects they may feel relevant to include in order to improve this experience.

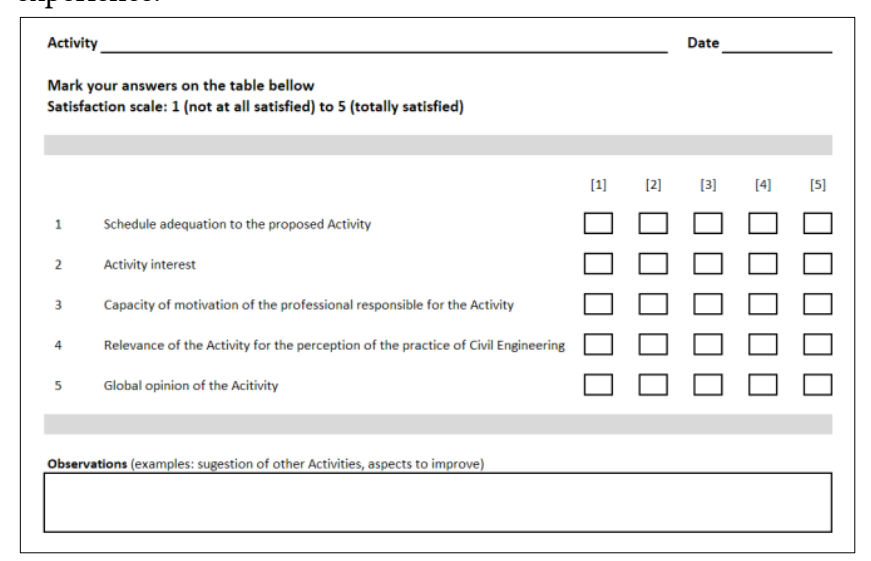

Figure 8: Enquiry sent to the students that participated on the activities

Of the total 27 participants only 11 responded to the proposed questionnaire. In spite of the reduced sample, the direction board of the degree opted to present its results, considering this initiative is still being developed on an experimental basis.

The 11 answers present a very reduced dispersion, contemplating only the two values: very and totally satisfied (values 4 or 5). Of those, more than $80 \%$ of the students were totally satisfied with the motivation skills of the engineers at the companies for the practice of civil engineering, and more than $60 \%$ were totally satisfied with the both the interest of the activity and in terms of global opinion on the activity.

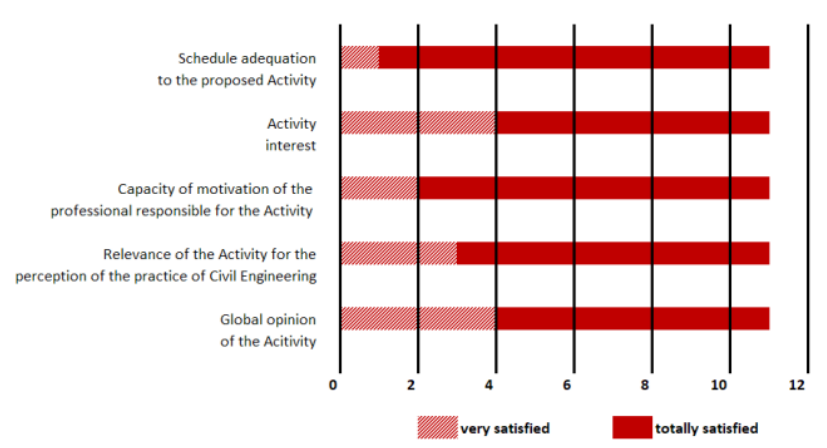

Figure 9: Inquiry results

The students participating on visits to construction sites were the only ones suggesting they were willing to redo the same activity in order to have a perception of the evolution of the construction. No aspect was mentioned for improvement.

After each visit, an informal contact between a member of the direction of the degree and the person in charge of the visit at the company was promoted. All information collected was, in general, very positive, except for the cases of the student's failure to attend the activity.

\section{Conclusions and Future Developments}

The initiative EngenheiroCivil@Work was implemented for the first time on the current academic year (2018/19). It involves an elevated number of stakeholders between students, teachers, companies and fellow civil engineers at the companies.

The direction of the degree has felt some difficulty on the implementation of this initiative, mainly attending to the large number of schedules to be compatibilized and the relative reduced number of possible windows of opportunity available. The second semester showed some increased difficulty due to the difficulty of having to program activities back in November when most of the remaining student activities were not yet known or could not be foreseen.

The activity is currently being monitored attending to several aspects, including the student's presences, answers to the questionnaires and contacts with the companies.

All the participants that responded to the enquiries have a very positive evaluation of the activity and mainly of its interest on the early increment of motivation of the students for the practice of Civil Engineering.

One of the aspects that must be improved is the number and control of the presence of the students, mainly due to the difficulty of compatible schedules which resulted on some activities that did not took place.

Aware of the relative shortcomings evidenced on the first year of implementation of this initiative the authors are considering several mitigating solutions, including the increase of number of students per visit or, for instance, the inclusion of the activities on the syllabus of first-year curricular units. The full set of activities proposed for the academic year must be defined earlier, including the activities of the degree, departmental activities, evaluation 
moments and the activities of this initiative. These moments of interaction should begin earlier in the first period (October or November) allowing a longer duration of time for the activities to happen and on period when the students show greater availability.

This innovating initiative was possible with the collaboration and effort of all parts involved and the direction of the degree feels that it may be a contribution for increased sustainability of the degree, helping the maintenance of the number of students and increasing their motivation with consequent better results and an improved understanding of the profession they chose.

\section{ACKNOWLEDGMENTS}

The authors would like to express their gratitude to all students, teachers, companies and fellow civil engineers at the companies involved for their collaboration.

\section{REFERENCES}

[1] IMPIC, "Relatório: O Sector da Construção em Portugal-2017", 2019(online), Available:

http://www.impic.pt/impic/assets/misc/relatorios_dados_estatisticos/ RelConst 2018 S1.pdf

[2] FEPICOP - Federação Portuguesa da Indústria da Construção e Obras Públicas. Quebra na Produção da Construção. Revista Conjuntura da Construção, v. 58, 2012

[3] https://www.dges.gov.pt

[4] http://www.isep.ipp.pt/New/ViewNew/5405

[5] Despacho ISEP/P/23/2017, Regulamento do Programa de Embaixadores do ISEP

[6] "Problem-based learning: student perceptions of its value in developing professional skills for engineering practice”; Una Beagon ,Dervilla Niall \&Eabhnat Ní Fhloinn;Received 27 Apr 2018, Accepted 10 Oct 2018, Published online: 16 Oct 2018

[7] Knowledge creation and innovation in a civil engineering course for the firstyear university students;Alpo Salmisto \&Petri Nokelainen;Pages 506-521 Received 08 Dec 2013, Accepted 14 Aug 2014, Published online: 07 Nov 2014 